\title{
Tipografia em livros didáticos de letramento e alfabetização: um estudo sob a perspectiva da semiótica
} Typography in literacy textbooks: a study from the perspective of semiotics

\author{
Marina Arakaki, Eluiza B. Ghizzi, Mariano L. de Andrade Neto \& Olímpio José Pinheiro
}

semiótica peirciana, significação, tipografia

\begin{abstract}
No Brasil, os livros didáticos são instrumentos de ensino adotados pelas escolas públicas de Ensino Fundamental e Médio. Esses livros têm uma presença massiva no cotidiano dos estudantes do país, e foram escolhidos como objeto desta pesquisa. A seleção dos livros utilizados nas escolas públicas é feita pelo Ministério da Educação (MEC), por meio do Programa Nacional do Livro Didático (PNLD), do Governo Federal. No processo de desenvolvimento dos livros, cabe ao designer atuar como um projetista da comunicação verbo-visual, fazendo a mediação entre os conteúdos específicos e os leitores. Esta mediação se dá por meio do planejamento e execução do projeto gráfico. Para essa pesquisa, selecionaram-se dois livros didáticos de Letramento e Alfabetização destinados ao primeiro ano do Ensino Fundamental, para análise dos elementos de seu projeto gráfico, especialmente, os elementos tipográficos, considerando que é por meio desses últimos que a criança terá contato com as práticas de leitura. Foi selecionada a metodologia de análise da semiótica peirciana. Como resultados, destacam-se as diferenças, semelhanças e efeitos de significado dos projetos gráficos e tipográficos analisados.
\end{abstract}

\section{Peirce's semiotic, signification, typography}

In Brazil, textbooks are teaching instruments adopted by public elementary and middle schools. These books have a massive presence in the daily life of the students of the country and were chosen as the object of this research. The selection of books used in public schools is done by the Ministry of Education (MEC), through the Didactic Book National Program (PNLD) of the Federal Government. In the process of book development, it is design responsibility to plan the verbal-visual communication, mediating the specific content and readers. This mediation takes place through the designing and execution of the graphic project. For this research, it was selected two literacy textbooks of the first year of elementary school to analyze the elements of their graphic design, especially the typographic elements, considering that it is through the latter that the children will have contact with reading practices. We selected the Peircian semiotic analysis as method. As results, we highlight the differences, similarities, and effects of the meaning of the graphic and typographic projects analyzed.

\section{Introdução}

No Brasil, os livros didáticos são instrumentos de ensino adotados pelas escolas públicas de Ensino Fundamental e Médio. Consequentemente, esses livros possuem uma presença massiva no cotidiano dos estudantes.

A seleção dos livros utilizados nas escolas públicas é feita pelo Ministério da Educação (MEC), por meio do Programa Nacional do Livro Didático (PNLD), do Governo Federal, que tem como 'principal objetivo subsidiar o trabalho pedagógico dos professores por meio da distribuição de coleções de livros didáticos aos alunos da educação básica' (Brasil, 2012).

O MEC avalia as obras conforme critérios publicados em edital, sendo que aquelas com pontuação suficiente constam no Guia de Livros Didáticos do PNLD, editado trienalmente. Esse guia é enviado às escolas públicas, que escolhem aqueles que melhor atendem ao seu projeto político e pedagógico.

No processo de desenvolvimento de livros didáticos, cabe ao designer atuar como um projetista da comunicação verbo-visual, fazendo a mediação entre os conteúdos específicos e os leitores. O projeto gráfico é o meio pelo qual o designer elabora a comunicação desses

Anais do 9 CIDI e 9 CONGIC

Luciane Maria Fadel, Carla Spinillo, Anderson Horta, Cristina Portugal (orgs.)

Sociedade Brasileira de Design da Informação - SBDI

Belo Horizonte | Brasil | 2019

ISBN 978-85-212-1728-2
Proceedings of the 9th CIDI and 9th CONGIC

Luciane Maria Fadel, Carla Spinillo, Anderson Horta, Cristina Portugal (orgs.)

Sociedade Brasileira de Design da Informação - SBDI Belo Horizonte | Brazil | 2019

ISBN 978-85-212-1728-2 
conteúdos aos leitores. Ele atua sobre todo o livro, mais especificamente sobre os elementos gráficos, tais como os tipográficos, as cores, as imagens, os materiais para capa e miolo, entre outros.

Dentre os elementos que compõem um projeto gráfico, nos livros didáticos de Letramento e Alfabetização, os elementos tipográficos tornam-se especialmente importantes, pois é por meio deles que a criança terá contato com as práticas de leitura.

Pode-se definir como aspectos (ou elementos) tipográficos de um livro, a tipografia (fonte, tipo de letra), sua constituição em blocos de textos e sua forma de distribuição, a escolha das entrelinhas e espaçamento entre caracteres e tudo que estiver relacionado ao uso de tipos ${ }^{1}$.

Com o advento da editoração eletrônica, as possibilidades de criação de um projeto gráfico e tipográfico são inúmeras, dada a variedade de fontes disponíveis, além das possibilidades de se criar tipos especiais para cada projeto. É justamente essa variedade que estimula a pesquisa dos processos significativos implicados nessas escolhas tipográficas, considerando 0 que é apropriado à necessidade de comunicação em cada caso.

Com base nas ferramentas que a teoria semiótica de Peirce proporciona, especialmente no estudo da interpretação, associados aos conhecimentos específicos sobre tipografia, este estudo teve como objetivo analisar o projeto gráfico e, especialmente o uso da tipografia, nos livros didáticos de Letramento e Alfabetização do $1^{\circ}$ ano do Ensino Fundamental, aprovados pelo PNLD 2013.

Das 12 coleções de livros escolhidas pelas escolas da Rede Municipal de Ensino de Campo Grande (REME) para a fase de Letramento e Alfabetização, foi selecionado o livro mais adotado entre as instituições (Projeto Buriti Português 1 - PBP1) e o menos adotado (Mundo Amigo - Língua Portuguesa 1 - MALP1) para serem analisados, buscando compará-los.

A escolha de livros do $1^{\circ}$ ano do ensino fundamental partiu da premissa de que a tipografia tem especial destaque nos livros dessa etapa escolar, pois é quando a criança está se familiarizando com a leitura.

\section{Normas tipográficas para textos infantis}

Após levantamento realizado na literatura disponível, elencou-se algumas práticas indicadas para a tipografia para textos infantis:

Em relação à fonte:

- Alguns autores defendem que as fontes cursivas são melhores para crianças que as tipo bastões (Heitlinger, 2009), sendo a característica mais importante que a fonte possua uma linha de saída (Sassoon citado em Lourenço, 2011), contudo, há também autores que defendem o uso da fonte bastão, por ser considerada de mais fácil aprendizagem, devido a seus traços simples;

- As fontes sem serifa seriam mais adequadas às crianças que as serifadas (Rocha, 2012; Lourenço, 2011);

- O tamanho deve ser entre 18 e 24 pontos, contudo, deve-se observar o tamanho visual da fonte, que muda conforme o tipo escolhido, e também se a fonte está apenas em maiúsculas ou em maiúsculas e minúsculas (Casarini \& Farias, 2008; Lourenço, 2011).

Em relação às linhas:

- O ideal seria entre 45 e 75 caracteres quando houver apenas uma coluna de texto (Bringhurst, 2011);

- O espaçamento entre letras deve ser maior do que em textos para adultos, contudo, sem perder a unidade da palavra (Bringhurst, 2011);

\footnotetext{
${ }^{1}$ Sinônimo de caractere. Cada letra, numeral ou sinal para-ortográfico de uma fonte
} 
Arakaki, M., Ghizzi, E. B., Andrade Neto, M. L., Pinheiro, O. J.। Tipografia em livros didáticos de letramento e alfabetização: um estudo sob a perspectiva da semiótica

- O espaçamento entrelinhas ideal é de 0,66 cm ou o espaço suficiente para que a criança acompanhe a leitura com os dedos (Casarini \& Farias, 2008; Lourenço, 2011; Bringhurst, 2011);

- O espaçamento entre palavras deve ser maior do que os utilizados em textos para adultos (Willberg \& Forssman citado em Lourenço, 2011).

Em relação ao bloco de texto:

- Recomenda-se o uso de textos alinhados à esquerda ou à direita, que não alteram o espaçamento entre cada palavra (Lourenço, 2011).

\section{Metolodogia}

Das 28 coleções de livros de Letramento e Alfabetização aprovadas pelo PNLD 2013, 12 foram selecionadas pelas escolas públicas de Campo Grande para serem utilizadas em 2013.

Tabela 1: Livros aprovados pelo PNLD 2013 de Letramento e Alfabetização escolhidos pelas Escolas de Campo Grande (REME - Campo Grande)

\begin{tabular}{l|l|l}
$\mathbf{N}$. & Títulos das Coleções & Total de Escolas \\
\hline 1 & Projeto Buriti & 25 \\
\hline 2 & Porta aberta & 24 \\
\hline 3 & Ápis & 18 \\
\hline 4 & Brasiliana & 4 \\
\hline 5 & A escola é nossa & 3 \\
\hline 6 & Projeto Pitanguá & 3 \\
\hline 7 & Projeto Prosa & 3 \\
\hline 8 & Linhas e entrelinhas & 3 \\
\hline 9 & Plural & 1 \\
\hline 10 & Bem-me-quer & 1 \\
\hline 11 & Viraver & 1 \\
\hline 12 & Mundo amigo & 1 \\
\hline
\end{tabular}

Decidiu-se analisar o livro mais adotado pelas escolas, o PBP1, e o menos adotado, o MALP1, e realizar um estudo comparativo entre eles, que ficam nos extremos da tabela, quanto ao projeto gráfico e tipográfico.

Quanto ao livro menos selecionado, houve um empate. Em contato telefônico com a responsável pela elaboração da lista, fomos informados de que a ordem de aparecimento dos livros que estão 'empatados' é aleatória. Optou-se pelo livro MALP1, pois foi encontrado com maior facilidade. 
Arakaki, M., Ghizzi, E. B., Andrade Neto, M. L., Pinheiro, O. J. | Tipografia em livros didáticos de letramento e alfabetização: um estudo sob a perspectiva da semiótica

\section{Livro Projeto Buriti Português 1}

Figura 1: Projeto Buriti Português 1 (Editora Moderna, 2010)

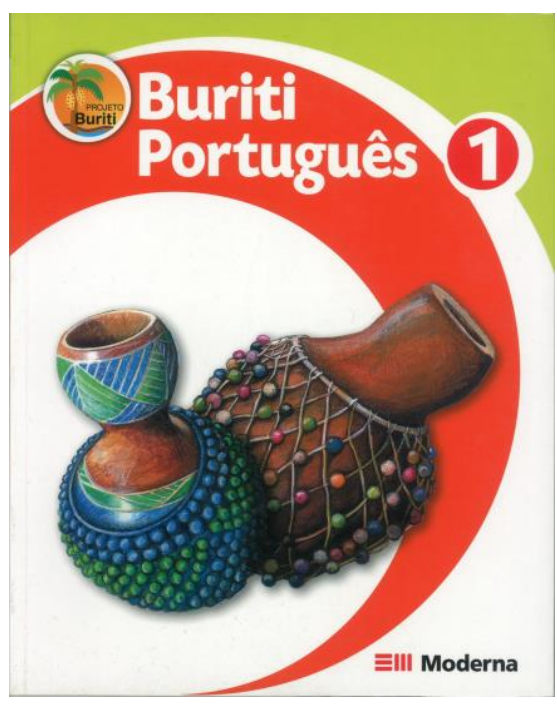

Os textos são, na grande maioria, impressos na cor preta, contudo, em títulos e, em parte das atividades, eles são coloridos, com cores saturadas e intensas. As letras são grandes e em sua maioria em caixa alta.

Percebe-se que ele possui uma lógica de disposição tipográfica, iniciando as primeiras unidades com as letras totalmente em maiúsculas, passando por unidades que mesclam letras maiúsculas e minúsculas e, por fim, utilizando as letras maiúsculas somente nos títulos, nomes próprios e início de frases (conforme as regras da língua portuguesa). A partir da percepção dessa característica, as páginas 18-19 foram selecionadas para serem analisadas no presente estudo.

Figura 1: Páginas 18 e 19 do livro Projeto Buriti Português 1 (Editora Moderna, 2010, p.18-19)

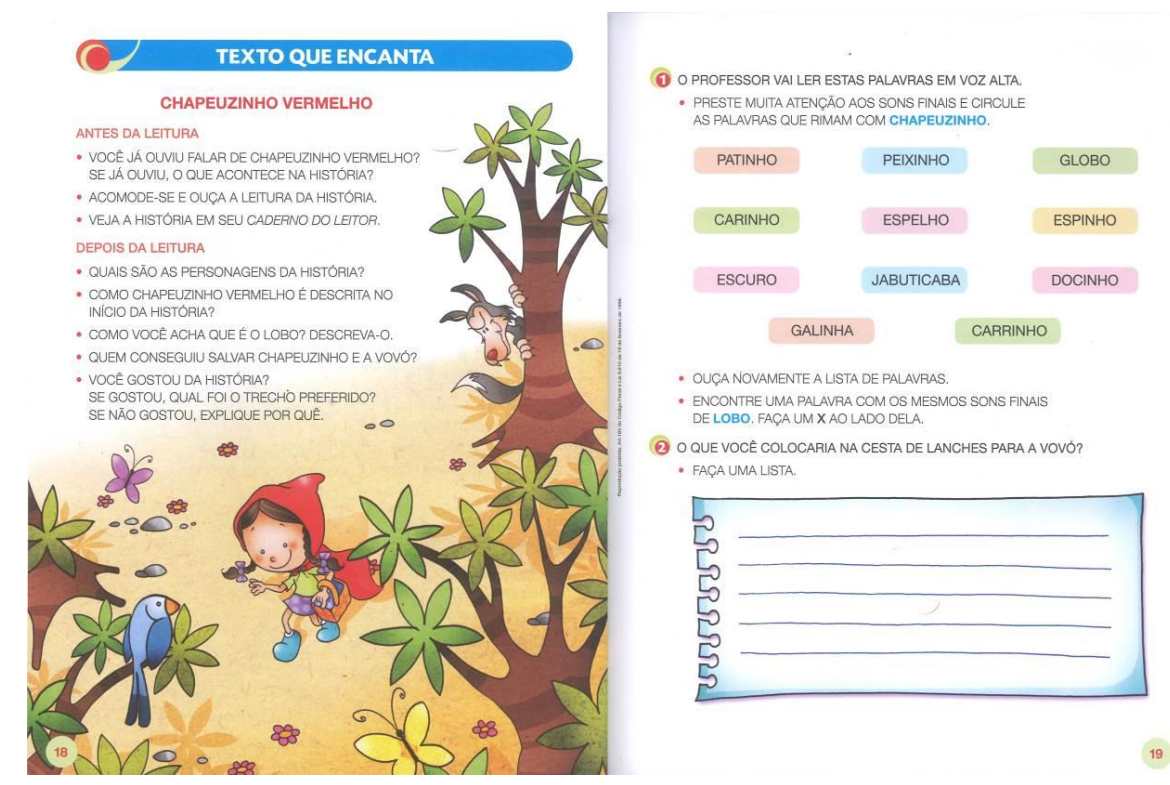


Arakaki, M., Ghizzi, E. B., Andrade Neto, M. L., Pinheiro, O. J. |

Tipografia em livros didáticos de letramento e alfabetização: um estudo sob a perspectiva da semiótica

\section{O signo em si mesmo}

Apesar da análise estar focada nos elementos tipográficos, optou-se por abranger também os elementos gráficos e imagéticos, pois eles influenciam a percepção não só do livro como um todo, mas também podem associar seus significados à tipografia.

Foram utilizadas duas fontes: no título principal da página da esquerda e para a numeração dos exercícios, e outra para os textos de leitura e atividades. A fonte utilizada na maior parte do texto (denominada de massa de texto principal - Figura 3) possui hastes uniformes, corpo dos caracteres visualmente leve, miolos bastante abertos, barras retas, sem serifa, composta em caixa alta.

Figura 2: Massa de texto principal (Editora Moderna, 2010, p.18)

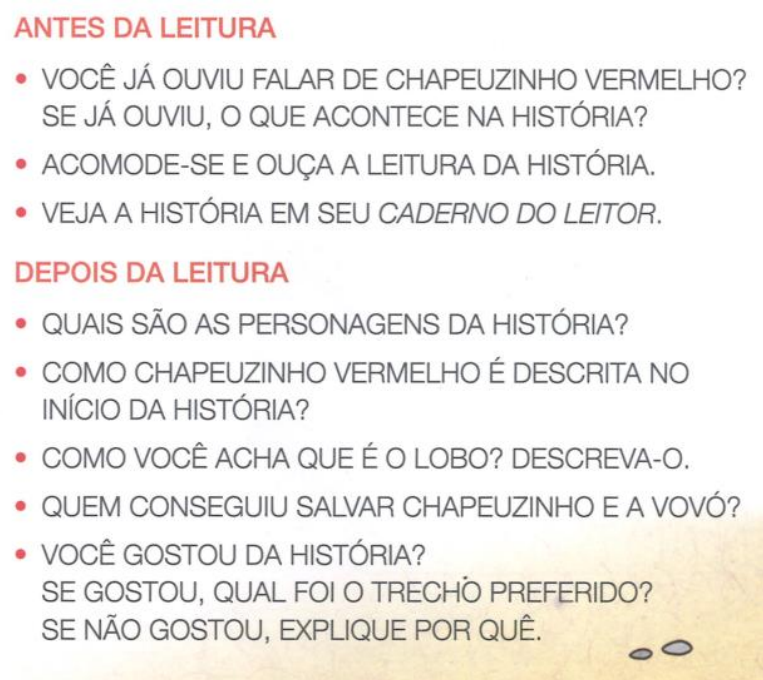

A fonte do título principal e da numeração de atividades é caracterizada por hastes com pouco contraste de espessura, corpo dos caracteres visualmente pesado, miolos com pouca abertura, barras retas, sem serifa, composta em caixa alta.

As linhas da massa de texto principal estão em caixa alta e possuem uma média de 44 caracteres, aproximadamente $12 \mathrm{~cm}$, dispostas em tópicos. Encontram-se alinhadas à esquerda, com espaçamento fixo entre as palavras.

Por meio dos traços distintivos da forma da fonte do texto principal (Figura 4), constatou-se que ela pertence à família Helvetica, utilizada em tamanho próximo do $14^{2}$, sendo um fundamento da ordem geral do signo.

Figura 3: Detalhes que possibilitam a identificação da fonte

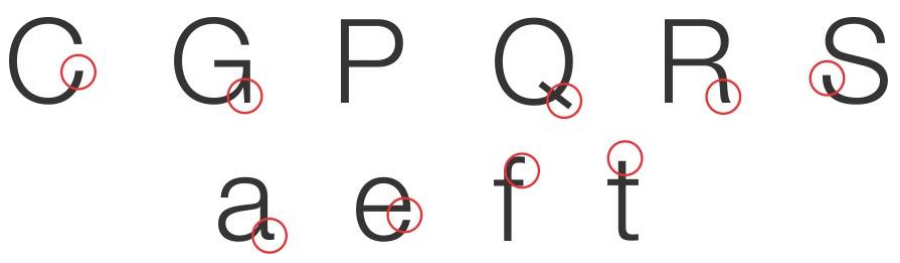

A Helvetica foi lançada com o nome de Haas Grotesk, passou por redesenhos que acrescentaram pesos à família, sendo rebatizada de Neue Helvetica. Desde sua criação, ela

\footnotetext{
214 pontos didot

Anais do 9o Congresso Internacional de Design da Informação | CIDI 2019

Proceedings of the 9th Information Design International Conference

Anais do $9^{\circ}$ Congresso Nacional de Iniciação Científica em Design da Informação | CONGIC 2019

Proceedings of the $9^{\text {th }}$ Information Design Student Conference
} 
vem sendo utilizada amplamente e, segundo Lupton (2006, p.42), 'é uma das fontes mais usadas do mundo', o que confere a ela um caráter altamente convencional.

\section{O signo e seus objetos}

Pode-se considerar, do ponto de vista do texto como uma escrita em uma língua, que o objeto imediato da massa de texto é o modo como os próprios símbolos dessa escrita utilizada na composição do texto estão apresentados na página (letras, pontuação, palavras), e seu objeto dinâmico, o alfabeto latino e a ideia geral que esses símbolos representam.

Do ponto de vista da tipografia, o objeto imediato da massa principal de texto é o modo como a grafia própria da fonte Helvetica aparece no texto, suas formas particulares e diferenças sutis de uma letra para outra, que permitem identificar sua família (objeto dinâmico). Mas a pergunta que interessa aqui é 'a que se referem esses símbolos nessa grafia em específico?', 'Qual é o propósito dessa grafia e não de outras para representá-los?' Uma possível resposta, no caso de livros didáticos de Letramento e Alfabetização, é a de que essa escolha tem como objetivo viabilizar o processo de aprendizado das regras de leitura. Para isso, todavia, é preciso que os símbolos tipográficos sejam legíveis. O objeto dinâmico, então, são as regras para elaborar um bom projeto tipográfico direcionado às crianças, e o objeto imediato é o modo como essa grafia constitui-se em uma regra, a escolhida e utilizada no livro em questão.

A fonte tem aproximadamente 14 pontos, o que, de acordo com Casarini \& Farias (2008), seria pequena para a idade em questão. Contudo, por ser utilizada em letras maiúsculas, transmite a impressão de que a fonte é maior do que seu tamanho em pontos. Dessa forma, considerou-se que a fonte está em tamanho adequado, pois, caso as letras fossem maiores, as linhas do texto ficariam ainda mais curtas, o que poderia causar hifenizações e mais movimentos sacádicos para a apreensão da palavra, prejudicando a leiturabilidade, causando fadiga.

A fonte da família Helvetica utilizada tem estilo bastão, o que, segundo alguns autores (Heitlinger, 2009; Lourenço, 2011), é menos favorável ao reconhecimento de caracteres que a fonte cursiva. Entretanto, deve-se ressaltar que a escolha dessa fonte pode ter motivos pedagógicos, por ser fácil ensinar a desenhá-la, devido à sua simplicidade de composição.

Conforme Clair \& Busic-Snyper (2009), a exposição do leitor a tipos de letras com as quais ele já é familiarizado é mais confortável para ele, devido à sua experiência de aprendizado. Nesse sentido, utilizar a fonte Helvetica pode facilitar a apreensão da leitura pois, como já dito, é uma das fontes mais utilizadas do mundo.

O texto, composto em linhas curtas, segundo a classificação de Bringhurst (2011), favorece uma rápida leitura.

As entrelinhas de $0,5 \mathrm{~cm}$ usadas nas páginas estão próximas do que Casarini \& Farias (2008) consideram ideal para a idade, auxiliando na legibilidade.

Para Rumjanek (2009) e Araújo (2011), o processo de leitura infantil ocorre por operações de análise e síntese, ou seja, a partir das menores unidades (as letras), para sílabas e outras unidades mais complexas. Ou seja, a criança lê letra por letra, o que leva a supor que o desenho da palavra não é tão importante quanto o desenho do caractere. Pode-se alegar que o uso de letras maiúsculas em estilo bastão poderia servir no ensino da escrita, devido à sua composição por meio de formas simples; também pode-se argumentar que, pedagogicamente, a utilização de letras maiúsculas facilitaria a compreensão da criança, por ela não ter de lidar com as regras ortográficas nessa etapa de ensino. Mesmo com todos esses argumentos, as minúsculas possuem uma maior diferenciação entre si do que as maiúsculas, assim, pelo viés imagético, a utilização das letras em caixa alta e baixa proporciona melhor reconhecimento dos caracteres e das palavras.

\section{O signo e seus interpretantes}

A utilização de cores saturadas nas páginas pode estimular interpretantes emocionais, pois, segundo Farina (1990), esse tipo de composição pode atrair a atenção do receptor devido à 
sua vivacidade. $O$ autor afirma que as cores utilizadas (azul, vermelho e verde, em grande parte das páginas) tendem a ser associadas com sentimentos de bem estar, euforia e dinamismo. Pode-se inferir que essa associação seja benéfica ao aprendizado, pois, conforme Piaget (1999), o despertar do interesse (por meio das cores e suas associações) da criança estimularia o processo de aprendizagem.

No que diz respeito ao texto, na fonte da família Helvetica, que pretende ser prática e neutra (Spiekermann, 2011), o estímulo emocional é de sobriedade e seriedade, conflitando com o despertado pelo colorido. A alta familiaridade da criança com a fonte pode trazer conforto e facilitar seu reconhecimento.

Como interpretante energético, pode-se citar o esforço das crianças para reconhecer cada letra e decifrar o conteúdo semântico. Ainda nesse nível do interpretante, podemos citar sua leiturabilidade, ou seja, o conforto visual envolvido na diagramação das páginas. Percebe-se que a utilização da fonte segue, mesmo que não inteiramente, as normas para composição de textos direcionados a crianças, indicando que ela possui uma boa leiturabilidade.

Ainda no interpretante energético, em relação ao próprio desenho da fonte, ela possui características que beneficiam sua legibilidade. Seu desenho proporciona boa diferenciação entre cada caractere, não havendo caracteres que normalmente são confundidos pelas crianças (Rumjanek, 2009), como o 'a' e o 'o' e o 'l' e o 'i' muito parecidos. O fato de ela não possuir serifas, ser utilizada em um tamanho adequado à idade do público-alvo, estar diagramada em linhas curtas, alinhadas à esquerda e com grande espaçamento nas entrelinhas, faz com que o esforço realizado pela criança seja minimizado.

O texto da massa principal encontra-se dividido em tópicos; a sequência (a mesma usada na escrita ocidental em geral) faz com que a criança siga uma ordem de leitura de modo 'natural'; e a divisão a obriga a paradas, reagindo à forma como o texto está organizado na página.

Em relação às ilustrações, elas (especialmente a ilustração da fábula) agem como signos complementares ao texto; apresentam o contexto dos textos acima como no caso da cor do título da fábula (na cor vermelha) e podem fazer a criança associar iconicamente o desenho ao texto. Conforme Rumjanek (2009), na primeira fase do aprendizado da leitura, as crianças costumam utilizar as informações visuais disponíveis para tentar decifrar o texto; isso considerado, tende-se a ler essas associações complementares como um interpretante lógico.

Por último, o interpretante lógico pode ser associado à legibilidade das letras, uma vez que sua definição refere-se ao reconhecimento individual de caracteres e, para isso, a criança precisa ter assimilado as normas da leitura. Pelos fatores descritos, esse interpretante estaria favorecido pelas formas da fonte. 
Arakaki, M., Ghizzi, E. B., Andrade Neto, M. L., Pinheiro, O. J. | Tipografia em livros didáticos de letramento e alfabetização: um estudo sob a perspectiva da semiótica

\section{Livro Mundo Amigo - Língua Portuguesa 1}

Figura 4: Mundo Amigo - Língua Portuguesa 1 (Edições SM, 2012)

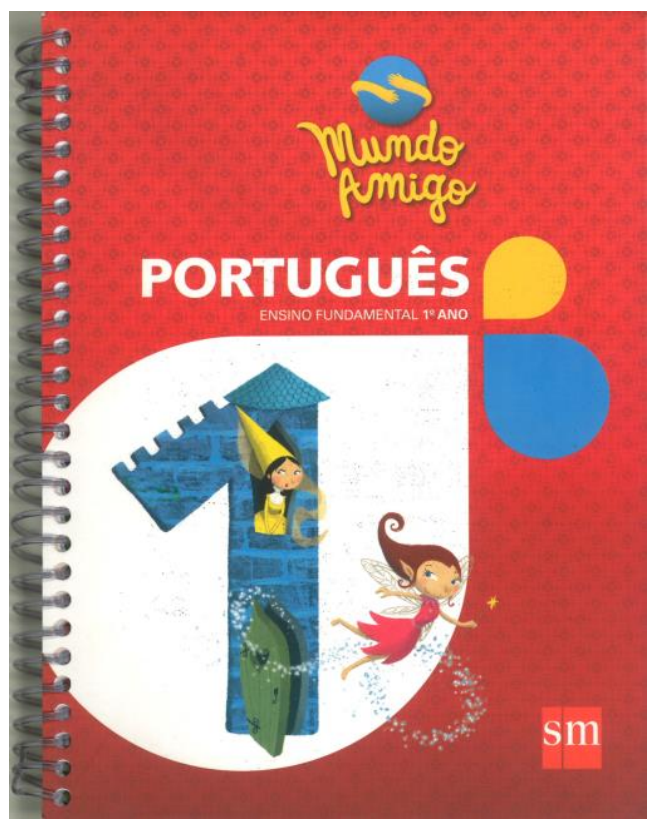

Os textos são em sua grande maioria impressos na cor preta, porém há títulos, letras cursivas, e outros tipos de fonte em outras cores. As letras são grandes e em sua maioria em caixa alta.

A distribuição tipográfica do livro MALP1 segue a lógica de utilizar nos capítulos iniciais somente maiúsculas, contudo, sua organização é menos clara quanto à introdução das minúsculas, aparecendo, posteriormente, capítulos com organização variada nos usos das maiúsculas e minúsculas. Verificou-se que o livro utiliza fontes bastões e cursivas em uma grande quantidade de páginas. Dadas essas razões, não foi possível estabelecer uma regra segundo a qual as variações ocorrem, sendo selecionadas para análise as páginas 38-39. 
Arakaki, M., Ghizzi, E. B., Andrade Neto, M. L., Pinheiro, O. J. | Tipografia em livros didáticos de letramento e alfabetização: um estudo sob a perspectiva da semiótica

Figura 5: Páginas 38 e 39 do livro MALP1 (Edições SM, 2012, p.38-39)

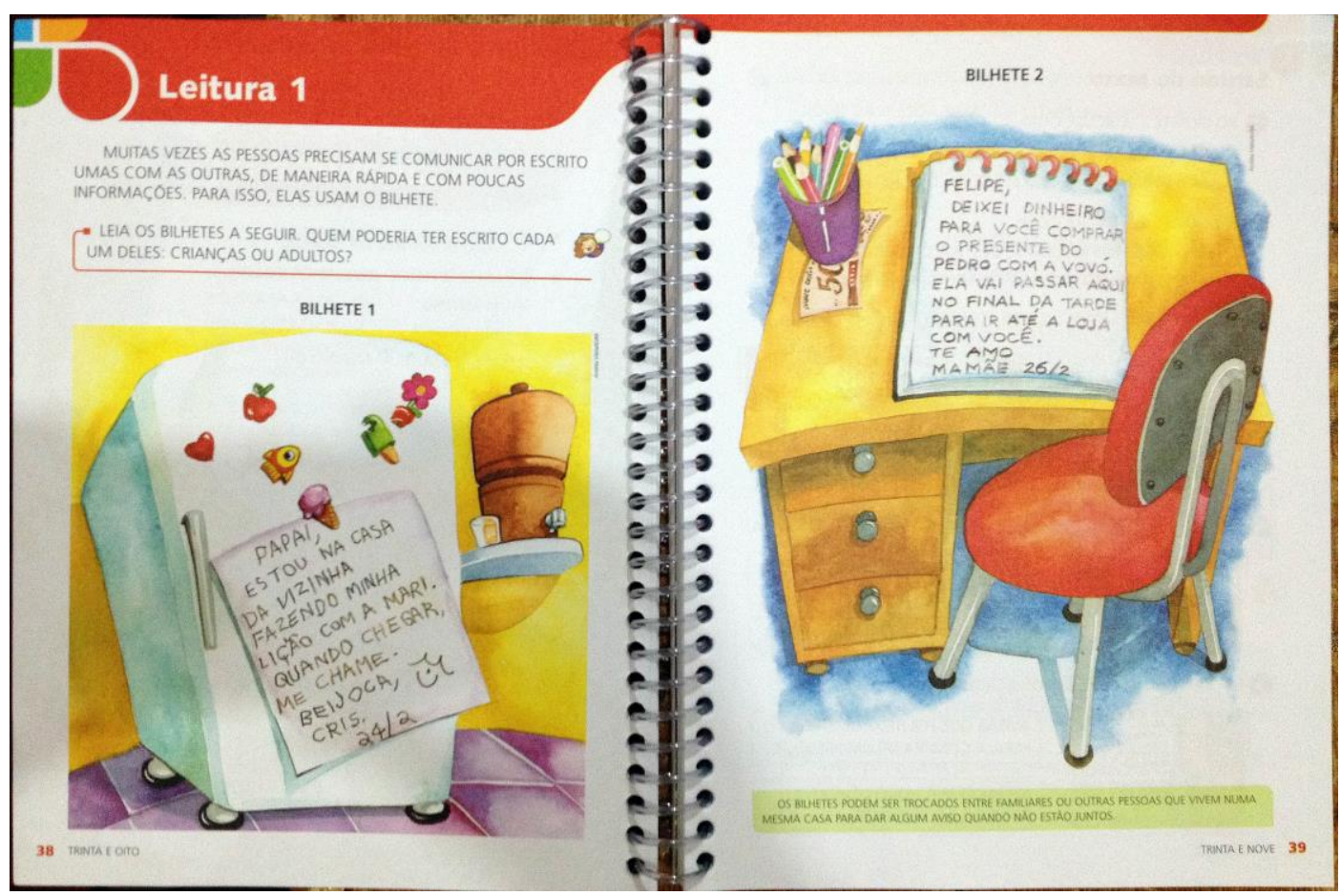

\section{O signo em si mesmo}

Em relação à tipografia, foram utilizados quatro tipos de fonte, conforme mostram em destaque as Figuras 7 a 10: uma para o título da parte didática do capítulo (Leitura 1) e para os títulos bilhete 1 e 2 (denominada fonte 1), outra para os dois blocos de texto (fonte 2), outra para o bilhete 1 (fonte 3 ) e outra, ainda, para o bilhete 2 (fonte 4 ).

Figura 6: Fonte 1 (Edições SM, 2012, p.38-39)

\section{Leitura 1}

\section{BILHETE 1}

BILHETE 2

Figura 8: Fonte 2 (Edições SM, 2012, p.38-39)

MUITAS VEZES AS PESSOAS PRECISAM SE COMUNICAR POR ESCRITO UMAS COM AS OUTRAS, DE MANEIRA RÁPIDA E COM POUCAS INFORMAÇŐES. PARA ISSO, ELAS USAM O BILHETE.

- LEIA OS BILHETES A SEGUIR. QUEM PODERIA TER ESCRITO CADA UM DELES: CRIANÇAS OU ADULTOS? 
Arakaki, M., Ghizzi, E. B., Andrade Neto, M. L., Pinheiro, O. J. | Tipografia em livros didáticos de letramento e alfabetização: um estudo sob a perspectiva da semiótica

Figura 9: Fonte 3 (Edições SM, 2012, p.38-39)

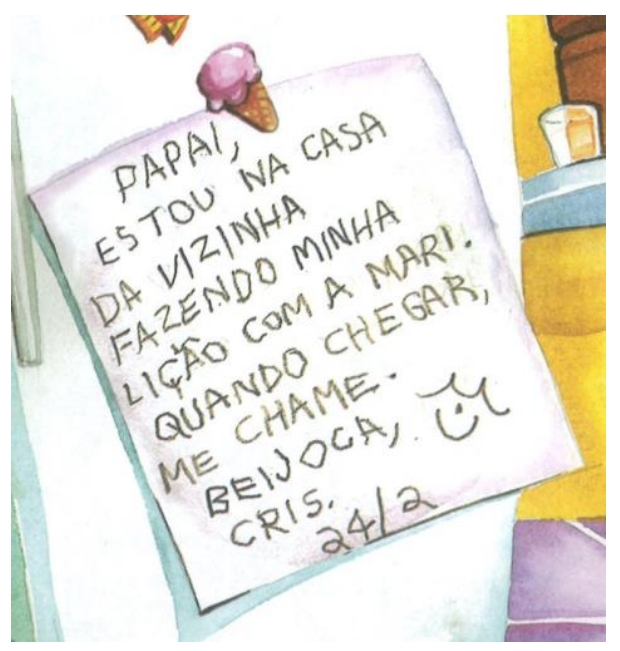

Figura 10: Fonte 4 (Edições SM, 2012, p.38-39)

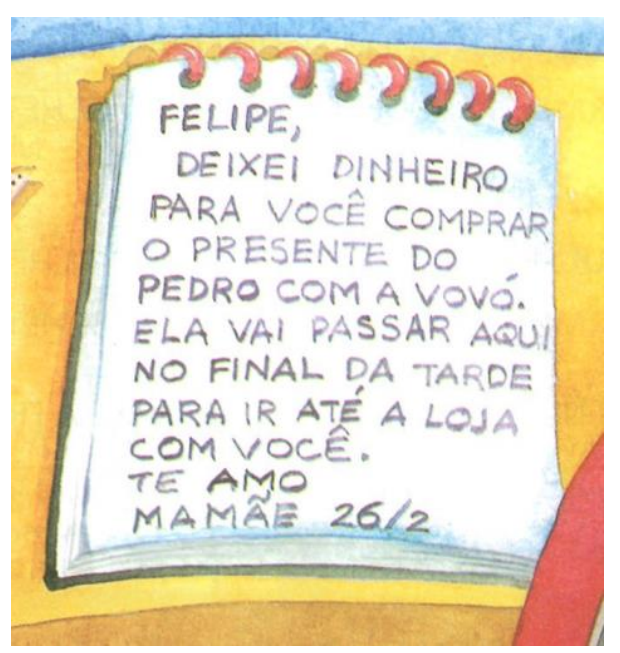

A fonte 1 possui hastes uniformes, corpo visualmente pesado, miolos não muito abertos, barras retas, sem serifa.

A fonte 2 é a mesma do título da parte didática, porém, com os caracteres visualmente leves, hastes uniformes, miolos abertos, barras retas, sem serifa.

A fonte 3 é uma forma que imita a escrita manuscrita. Seus caracteres são compostos por linhas trêmulas, em barras que se conectam algumas vezes, outras não. Possui um estilo visual primitivo, devido às irregularidades, simplicidade, distorções e espontaneidade. Algumas letras não possuem uniformidade nas repetições, sendo únicas em cada instância em que se apresentam; por exemplo, cada letra "A" do bilhete é de uma forma única, embora todas sigam um mesmo tipo geral, que é comum à letra "A" maiúscula. Seus miolos são predominantemente abertos e ela é visualmente pesada, texturizada e na cor preta.

A fonte 4 também imita a escrita manuscrita. Seus caracteres são compostos por linhas mais uniformes que as do primeiro bilhete, contudo, ainda se percebe certa diferença entre suas hastes. Possui barras retas, conectadas e uma maior similaridade entre cada caractere. Seus miolos são mais fechados, é visualmente pesada, texturizada e na cor preta. Observa-se um estilo visual funcional nessa fonte, devido a sua simplicidade, simetria e geometrização. 
Em todas as ocorrências de fontes da página, elas estão alinhadas à esquerda, sendo a fonte $2 \mathrm{com}$ espaçamento fixo e as fontes 3 e 4 com espaçamento variável, com maior intensidade de variação na fonte 3 .

As linhas da fonte 2 possuem uma média de 50 caracteres, com aproximadamente $16,5 \mathrm{~cm}$. Suas entrelinhas são variáveis, sendo maiores onde há mudança de parágrafo, com um recuo de $8 \mathrm{~mm}$.

No nível dos legissignos, pode-se constatar que as fontes utilizadas no título da parte didática, nos subtítulos e no parágrafo de texto (fontes 1 e 2) pertencem à família da fonte Frutiger (Figura 11), em tamanho próximo aos 14 pontos.

Figura 11: Detalhes que possibilitam a identificação da fonte

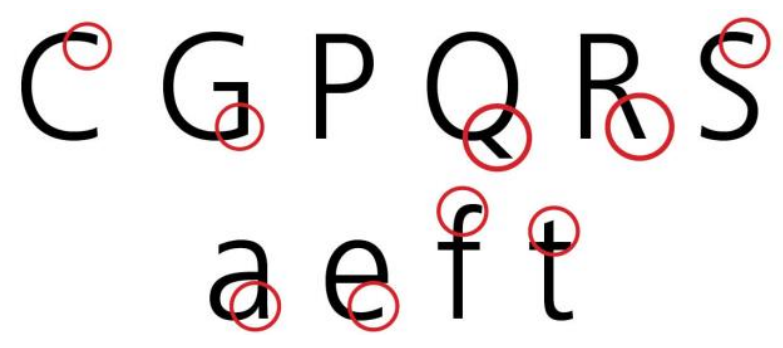

Adrian Frutiger projetou a fonte na década de 1970. Frutiger tentou unir nessa fonte a racionalidade e clareza da Univers com as formas orgânicas e proporcionais da Gill Sans, resultando numa fonte altamente legível.

Quanto ao texto da fonte 3, o que primeiro se pode perceber é que o posicionamento das linhas é diagonal em relação às margens do livro, quebrando a convencionalidade horizontal normalmente vista em textos. As letras possuem um aspecto texturizado que remete à escrita com lápis.

$\mathrm{Na}$ fonte 4 , o posicionamento horizontal reforça a convencionalidade, tornando-a mais fácil de ler que a fonte 3.

As formas mais regulares também permitem essa maior facilidade de leitura, porém, por haver pequenas diferenciações entre uma e outra e serem texturizadas, transmitem a ideia de que foram escritas por pessoas e não por uma máquina.

\section{O signo e seus objetos}

Em relação aos seus objetos, estabelece-se o mesmo raciocínio da análise anterior, contudo, o objeto dinâmico das fontes difere.

O objeto dinâmico das fontes 1 e 2 é a fonte Frutiger, e das fontes 3 e 4 seria a ideia geral dos caracteres latinos, visto que elas não pertencem a nenhuma fonte conhecida em particular.

Os sinssignos presentes, tais como a irregularidade e textura das fontes, distinguem 3 diferentes escritores. O autor do livro (fonte 1 e 2), a criança (fonte 3 ) e sua mãe (fonte 4).

Em relação à tipografia, as fontes 1 e 2, são em estilo bastão, mesmo caso da análise anterior. Nessas fontes, o texto também encontra-se em 14 pontos, e, pelo fato de estar em maiúsculas, pode ser considerado adequado.

A fonte 2 está composta em uma linha com 50 caracteres, que está dentro dos ideais (entre 45 e 75 caracteres); segundo Bringhurst (2011), facilita uma rápida leitura. O espaçamento entrelinhas, de $0,3 \mathrm{~cm}$, é considerado pequeno para a idade em questão, podendo prejudicar a legibilidade. O texto composto todo em maiúsculas não é o mais favorável para o reconhecimento dos caracteres, exigindo esforço de interpretação. 
A irregularidade e o posicionamento diagonal da fonte 3 , apesar de reforçar o caráter lúdico buscado nesse tipo de material, pode prejudicar a legibilidade. $O$ aspecto irregular e trêmulo das letras indica a escrita de uma criança. Não há como mensurar o tamanho da fonte, pois, por ser única, não há como compará-la, contudo, pode-se perceber que seu tamanho visual é maior do que o da fonte do parágrafo de texto acima dela. Ela está alinhada à esquerda, porém o espaçamento entre as palavras é irregular, assim como o espaçamento entrelinhas é pequeno para crianças $(0,3 \mathrm{~cm})$. Ao mesmo tempo, alguns pesquisadores (Coutinho \& Silva, 2006) e o próprio PNLD 2013 defendem a utilização de fontes variadas para que haja uma familiaridade com diversos textos e mensagens encontrados no cotidiano, tal como o exemplo do livro. Essa posição é contrária ao que diz Paulo Heitlinger (2009). Ressalta-se que consideramos adequado o uso de variadas fontes, mas por ela estar na diagonal, com espaçamento entrelinhas pequeno e muitos traços irregulares, essa fonte específica acaba prejudicando tanto a legibilidade como a leiturabilidade do texto.

A fonte 4, por estar na horizontal e por ter um espaçamento mais uniforme entre as palavras, favorece a leiturabilidade do texto, da mesma forma que suas hastes mais retas e regulares favorecem a legibilidade.

\section{O signo e seus interpretantes}

O texto em fonte Frutiger, planejada com o objetivo de ser informativa e legível (Spiekermann, 2011), transmite formalidade e sobriedade, conflitando com o caráter lúdico das ilustrações. As fontes utilizadas nos bilhetes possuem essa característica mais descontraída, podendo apreender a atenção e curiosidade da criança.

Como interpretantes energéticos, há o esforço em decifrar o conteúdo semântico. Os diferentes tipos de fontes utilizadas também podem causar esforço na decifração do texto, uma vez que ela precisará se adaptar a diferentes formatos de letras para ler cada mensagem.

A fonte do texto 2 proporciona uma boa leiturabilidade, o que geraria menos esforço na sua decifração. Em relação às fontes 3 e 4, a primeira possui uma leiturabilidade mais baixa que a segunda, mas ambas são menos confortáveis do que a fonte do texto 2 .

A forma como as ilustrações e a atividade estão distribuídas pode causar confusão na direção da leitura, pois, apesar de haver uma hierarquia de informações, ela se perde devido à grande atenção dada às ilustrações, trazendo, novamente, o esforço em saber por onde começar a leitura das páginas.

Nos interpretantes lógicos, as ilustrações integradas ao texto funcionam como símbolos, que tanto podem fazer a criança associar os desenhos com situações já vivenciadas, quanto são modelos do que se pretende que a criança aprenda, ou seja, de como fazer um bilhete.

Uma vez superada a barreira da decifração do sistema de linguagem das palavras, o texto dos dois bilhetes pode ser associado, no caso do texto colado à geladeira, com uma fonte desenhada por uma criança, devido aos traços trêmulos e linhas mais tortas, e, no caso do texto em cima da escrivaninha, com uma fonte desenhada por um adulto, devido aos traços mais firmes e retos. Isso cria uma situação de comunicação mais dinâmica, já que há diferentes autores dialogando com a criança; não se trata apenas do autor do livro como emissor e a criança como receptor, mas do livro como representação de uma situação comum do dia-a-dia, na qual esses diálogos se estabelecem.

\section{Conclusão}

Constatou-se que as preferências tipográficas variam de acordo com a cultura, a idade, a época, as experiências de vida etc. No entanto, apesar desse cenário heterogêneo, foram feitos esforços para elencar algumas normas estabelecidas sobre a tipografia direcionada a textos infantis. Essas normas serviram de base para as análises realizadas, juntamente com as referências sobre comunicação e aprendizagem infantil. 
A metodologia semiótica mostrou-se um meio de análise que, por entreter-se com diferentes aspectos do signo e das relações estabelecidas a partir dele, permite perceber características e efeitos em maior profundidade, bem como refletir sobre aspectos nem sempre abordados em estudos tipográficos.

Chegou-se à conclusão de que não existe apenas uma tipografia adequada ao público infantil; apesar disso, os aspectos que proporcionam uma melhor legibilidade e leiturabilidade devem ser respeitados, para que a diagramação do livro não interfira negativamente no processo de alfabetização e leitura infantil.

No livro PBP1, constatou-se uma organização estabelecida para o ensino da leitura e da escrita, de modo a introduzir progressivamente informações que permitam aos professores não ter que se comprometer com várias regras da escrita e leitura desde o início, introduzindo-as nos conteúdos das aulas à medida em que vão aparecendo no projeto gráfico. É perceptível a preocupação de seus desenvolvedores com um projeto gráfico que tornasse clara uma linha pedagógica para a utilização do livro.

O livro MALP1 não exibe a mesma clareza de organização em relação à utilização da tipografia, pois, ao longo do livro, mesclam-se letras maiúsculas e minúsculas, bem como vários tipos de fontes. Por outro lado, entendeu-se que o livro tem uma proposta de contato com a leitura bastante dinâmica, pois inclui situações de uso cotidiano da escrita e leitura para o aprendizado. Contudo, nem sempre as diretrizes de tipografia para crianças são respeitadas, em alguns casos, ocorrendo textos com tamanho de fonte pequeno, pouco espaçamento nas entrelinhas etc.

Não coube a esta pesquisa determinar se há um livro melhor entre os dois, mas indicar as diferentes estratégias visuais utilizadas nos projetos gráficos e tipográficos analisados. Esse objeto de estudo permite, ainda, outros desdobramentos no âmbito da semiótica; além disso, pode também receber contribuições de outras áreas, tais como o design da informação e a educação.

\section{Referências}

Araújo, A. (Org) (2011). Aprendizagem infantil: uma abordagem da neurociência, economia e psicologia cognitiva. Rio de Janeiro: Academia Brasileira de Ciências.

Brasil. (2012) Ministério da Educação - MEC. PNLD: Apresentação. Brasília, DF. Recuperado de portal.mec.gov.br/index.php?ltemid=668\&id=12391\&option=com_content\&view=article

Bringhurst, R. (2011) Elementos do estilo tipográfico (versão 3.2). 2. ed. São Paulo: Cosac Naify.

Casarini, P. C. \& Farias, P. L. (2008). Didactica - tipografia para livros didáticos infantis. InfoDesign, v. 2, n. 5, p. 63-71, São Paulo: SBDI. ISSN 1808-5377.

Clair, K. \& Busic-Snyder, C. (2009). Manual de tipografia: a história, as técnicas e a arte. Porto Alegre: Bookman.

Coutinho, S. G. \& Silva, J. F. L. (2006). Linguagem Visual em livros didáticos infantis. $15^{\circ}$ Encontro Nacional da ANPAP. Anais do $15^{\circ}$ Encontro Nacional. Arte: limites e contaminações. Salvador.

Farina, M. (1990). Psicodinâmica das cores em comunicação. 4. ed. São Paulo: Blucher. Hamaya, E. S. (2012). Mundo Amigo: Língua Portuguesa 1. 2 ed. São Paulo: Edições SM.

Heitlinger, P. (2009). Cadernos de Tipografia e Design, n. 14. São Paulo. Recuperado de http://tipografos.net/cadernos/cadernos-14.html

Lourenço, D. A. (2011). Tipografia para livro de literatura infantil: desenvolvimento de um guia com recomendações tipográficas para designers. Curitiba: Universidade Federal do Paraná. 
Arakaki, M., Ghizzi, E. B., Andrade Neto, M. L., Pinheiro, O. J. |

Tipografia em livros didáticos de letramento e alfabetização: um estudo sob a perspectiva da semiótica

Lupton, E. (2006). Pensar com tipos: guia para designers, escritores, editores e estudantes. São Paulo: Cosac Naif.

Editora Moderna. (2010). Projeto Buriti: Português 1. 2 ed. São Paulo: Editora Moderna.

Piaget, J. (1999). Seis estudos de psicologia. 24. ed. Rio de Janeiro: Forense Universitária.

Rocha, C. (2012). Novo projeto tipográfico: análise e produção de fontes digitais. São Paulo: Rosari.

Rumjanek, L. (2009). Tipografia para crianças: um estudo de legibilidade. Rio de Janeiro: dissertação de mestrado, Escola Superior de Desenho Industrial.

Spiekermann, E. (2011). A linguagem invisível da tipografia: escolher, combinar e expressar com tipos. São Paulo: Blucher.

\section{Sobre os autores}

Marina Arakaki, doutoranda, Unesp, Brasil <marina.arakaki@unesp.br>

Eluiza B. Ghizzi, doutora, UFMS, Brasil <eluizabortolotto.ghizzi@gmail.com>

Olímpio José Pinheiro, pós-doutor, Unesp, Brasil <oj.pinheiro@unesp.br>

Mariano Lopes de Andrade Neto, doutor, UniFSP, Brasil <mlaneto@gmail.com> 